\title{
Formación de maestría en contabilidad en Colombia: una comparación entre las expectativas de los aspirantes y los contenidos curriculares de los programas ${ }^{1}$
}

\author{
Paula Andrea Navarro Pérez ${ }^{2}$ \\ Laura Natalia Pulgarín García ${ }^{3}$ \\ Julián David Sandoval Alarcón $n^{4}$
}

Recibido: 9 de octubre del 2018

Aprobado: 10 de diciembre del 2018

Clasificación JEL: I21, M49

\section{Resumen}

El presente estudio tuvo como objetivo realizar un análisis comparativo entre las expectativas que tienen los estudiantes de contaduría pública,

1 Navarro, P. A., Pulgarín, L. N., y Sandoval J. D. (2019). Formación de maestría en contabilidad en Colombia: una comparación entre las expectativas de los aspirantes y los contenidos curriculares de los programas. Revista Activos, 16(31), 157-203. DOI: https://doi.org/10.15332/25005278.5319

Una versión preliminar de este trabajo fue presentada en el VI Encuentro Nacional y Primero Internacional de Profesores de Contaduría Pública organizado en el marco del Convenio de Cooperación Académica de Programas de Contaduría Pública.

2 Contadora pública, master of Business Administration. Fundación Universitaria Los Libertadores, Bogotá D. C., Colombia. Correo electrónico: panavarrop@ libertadores.edu.co.

3 Contadora pública, magíster en Ciencias Económicas (c). Universidad Nacional de Colombia, Bogotá D. C. Correo electrónico: lnpulgaring@unal.edu.co

4 Contador público, administrador de empresas, magíster en Contabilidad y Finanzas (c). Universidad Santo Tomás, Bogotá D. C., Colombia. julian.sandoval@ usantotomas.edu.co - ORCID: https://orcid.org/0000-0002-0299-4331. 
como potenciales aspirantes de la oferta educativa de los programas de maestría en contabilidad en Colombia, frente a lo que estos ofrecen, con el fin de medir las distancias euclidianas y determinar la brecha existente entre ambas dimensiones. Se evalúan dichas percepciones por medio de la aplicación de encuestas a estudiantes de pregrado de contaduría pública y se añade información de la oferta académica por medio de la recolección de los datos procedente de los planes de estudio y los perfiles de egresados. Como resultado se observó que las expectativas de los estudiantes de pregrado en contaduría acerca de las maestrías en contabilidad distan significativamente de lo ofrecido por las instituciones de educación en estos programas. Estas diferencias pueden ser explicadas por diversos factores como el desconocimiento de los estudiantes de pregrado acerca de las ofertas de posgrado o de las instituciones de educación acerca de las expectativas de los futuros profesionales, entre otros.

Palabras clave: Maestría en Contabilidad, formación maestral en contabilidad, áreas de formación, habilidades de formación, percepción estudiantil.

\title{
Master's degree in accounting in Colombia: a comparison between the expectations of the candidates and the curricular contents of the program
}

\begin{abstract}
In the present study, a comparative analysis is made between the perceptions that public accountancy students have about the educational offer of the master's programs in accounting in the country, compared to what those programs actually offer, in order to measure the Euclidean distances and determine the existing gap between both dimensions. These perceptions are evaluated through the application of surveys to undergraduate students of public accountancy. Furthermore, information regarding the
\end{abstract}


academic offer is added through the collection of data from curriculums and program profiles. As a result, it was observed that perceptions of undergraduate students in accounting for master's degrees in the same area are significantly different from those offered by higher education institutions in these programs. These differences can be explained by multiple factors such as the undergraduate students' unawareness about graduate offers or the higher education institutions' unawareness about the expectations of future professionals.

Key words: Master of Accounting, master's degree in accounting, training areas, training skills, students' perception.

\section{Introducción}

El contexto globalizado en el que nos encontramos hoy en día, con flujo de capitales y conocimiento moviéndose más fácilmente a nivel mundial, demanda de individuos capaces de romper las fronteras del conocimiento con formación óptima para el continuo soporte al desarrollo de la sociedad. En este sentido, con miras hacia el fomento del desarrollo, el crecimiento de las naciones y la innovación se ha hecho necesaria la continua formación de capital humano óptimo y capaz de afrontar las demandas del mundo cambiante. Como señala Jaramillo Salazar (2009):

Los recursos humanos son el punto de partida del crecimiento y la equidad, dentro de una clara concepción de que con una formación de alto nivel y calidad se logra producir y socializar el conocimiento, generando de esta manera ventajas permanentes para un desarrollo sostenible en el largo plazo. (P. 1).

Para el caso colombiano, el Estado reconoce también que, para impulsar el desarrollo humano, debe involucrarse el entorno económico, social, ambiental, cultural y científico del país a través de la inversión en capital 
humano representado principalmente por la educación (Ministerio de Educación Nacional, 2016, p. 14), sea primaria, secundaria o superior.

Particularmente, una de las áreas de formación que se ha fortalecido en las últimas décadas y se ha consolidado entre las más necesarias ha sido la contabilidad, ya que "ha influido e influye en el medio en el que se desenvuelve, condicionando y, por qué no, impulsando su configuración y su crecimiento" (Tua, 1995, p. 95). En este sentido, la profesión contable ha evolucionado de acuerdo con las dinámicas de globalización en la medida en que han surgido diversos organismos supranacionales con la función de emitir diferentes tipos de estándares de información para sincronizar las prácticas contables nacionales con la economía global (Castillo, Córdoba y Villareal, 2014). La disciplina contable, por su estrecha relación con la economía y por la naturaleza altamente influyente en la sociedad como lenguaje económico, se ha configurado como una de las áreas de formación profesional de mayor interés, lo cual se puede evidenciar en el crecimiento en los últimos años tanto de los programas que se ofrecen en esta disciplina como en el número de matriculados, argumento que se aborda, más adelante, en el documento.

Consecuentemente, se hace necesario desarrollar investigaciones que se enfoquen en la formación contable y sus diferentes ámbitos a nivel global y local. Para efectos de este análisis se toma como referente la educación superior posgradual, específicamente programas de Maestría en Contabilidad, puesto que los estudios que se han hecho en torno a la formación contable en Colombia han sido en su gran mayoría orientados hacia los programas de pregrado. En este sentido, se han generado en las últimas décadas múltiples investigaciones y reflexiones en torno al sentido de la disciplina contable y su orientación crítica (Gómez, 2016; Ospina, 2016), la interdisciplinariedad (Ariza, 2003; Ospina, 2016), los contenidos curriculares y los planes de estudio (Ariza y Soler, 2004; Barragán, 2009; Giraldo, 2013; Loaiza, 2013; Patiño y Santos, 2009; Patiño, Valero, Acosta, Parra y Bautista, 2016), el perfil profesional hacia el cual está orientada la profesión (Zapata, 1998), las estrategias e importancia de la docencia y la pedagogía (CárdenasLondoño, 2009; Cardona, 1998; Martínez, 2011; Rodríguez-Castro, 2010), 
el rol de la investigación en la profesión (Araújo, 2000), los componentes éticos y habilidades blandas (Herrera, 2013; Sánchez, 2011) y las dinámicas modernas de internacionalización de la educación contable mediante la propagación de las IES (Gómez, 2007; Vásquez-Bernal, 2002; Villareal, Martínez y Muñoz, 2016).

Por el contrario, a nivel de maestrías en el área contable en Colombia los estudios académicos han sido escasos, teniendo como ejemplo a Cerón (2012) quien en su texto trabaja directamente esta temática. No se evidencia un interés explícito por parte de la academia el estudiar los contenidos curriculares y los planes de estudio que se están ofreciendo a los estudiantes de maestría en contabilidad. Únicamente las universidades interesadas en registrar maestrías en el área contable han sido las encargadas de evaluar la pertinencia de dichos programas, los perfiles que se deberían ofertar y la estructura de los mismos. Sin embargo, desde la academia y la profesión, todavía no se han adelantado reflexiones profundas sobre estos programas y su incidencia en la disciplina contable como tal.

A nivel de Latinoamérica Hernández, Tamez, Leal y Garza (2013) llevaron a cabo un estudio en la Facultad de Contaduría Pública y Administración (FACPYA) de la Universidad Autónoma de Nuevo León, México, en el que se presentaron las expectativas relacionadas con el aprendizaje, interés laboral y económico de los aspirantes a la Maestría en Contaduría, utilizando la metodología expertones con lógica borrosa. De este estudio concluyeron que "las dos principales áreas de interés laboral para los futuros estudiantes son las finanzas y los impuestos, y que su interés está dirigido a laborar en la iniciativa privada" (p. 242).

De acuerdo con Crawford (2017) los cambios referentes a programas de maestría en las instituciones corresponden a cambios de factores externos a los establecimientos educativos más que a factores internos, correspondiendo mayoritariamente a la necesidad de profesionales mejor cualificados en entornos altamente competitivos, al igual que la tendencia de aumentar el nivel educativo en la educación. 
Es por lo anterior que en el actual trabajo se realizó una comparación de las expectativas que poseen los estudiantes de contaduría pública frente a la oferta educativa de los programas de maestría en contabilidad en el país, respecto a lo que ofrecen dichos programas. Para cumplir dicho trabajo se utilizaron las distancias euclidianas como instrumento de medición para determinar la brecha existente entre las expectativas de los estudiantes y las ofertas de las maestrías en contabilidad, utilizando encuestas y mallas curriculares como insumos principales para la determinación de las categorías de análisis.

El presente trabajo comienza haciendo una revisión de la normatividad vigente para los programas de posgrado en Colombia, para después realizar un análisis del comportamiento de los programas de educación superior en el área de contabilidad en Colombia y, además, presentar la conceptualización de las áreas disciplinares y las habilidades de los profesionales contables. Posteriormente, se aplica la metodología mencionada para determinar las divergencias entre las percepciones de los estudiantes de pregrado y la oferta académica de las maestrías en contabilidad, realizando un análisis de los resultados obtenidos. Finalmente, se presentan las conclusiones del estudio.

\section{Metodología}

Para el diseño metodológico de esta ponencia se parte de una revisión de la literatura para conocer el estado del arte de la investigación en torno a las percepciones de los estudiantes de pregrado sobre las maestrías en contabilidad y la oferta académica de las mismas. En esta revisión literaria se aborda la normatividad vigente aplicable a los posgrados en Colombia, el comportamiento de la oferta y la demanda de los pregrados en contaduría y maestría en contabilidad entre los años 2010 y 2018 y la conceptualización de las áreas y habilidades que componen dichos programas. A partir de ello, se seleccionan unas categorías de estudio comprendidas en siete áreas de formación: contabilidad estratégica, contabilidad financiera, contabilidad gubernamental, contabilidad impositiva, líneas interdisciplinares, sistemas 
y control y teoría contable; y cuatro habilidades de formación: investigación formal, capacidades interpersonales y de comunicación, pensamiento contable y técnica avanzada.

Posteriormente, se aplicaron encuestas a estudiantes activos de programas de pregrado de Contaduría Pública de la Universidad Nacional de Colombia, la Universidad Santo Tomás y la Fundación Universitaria Los Libertadores ${ }^{5}$. La finalidad de estas encuestas es recolectar información acerca de las expectativas que los estudiantes de pregrado de contaduría de las distintas universidades tienen sobre los contenidos programáticos de las maestrías en contabilidad. Esta encuesta fue contestada por un total de 252 estudiantes (ver Anexo 1).

En contraste, se recolecta información de los planes de estudio y los contenidos de las siete maestrías ${ }^{6}$ activas en contabilidad en Colombia de acuerdo con datos provenientes del SNIES (ver Anexo 2). Esta información corresponde al plan de estudios periódico en cada uno de los programas ofertados, donde se detallan las áreas de conocimiento y líneas de profundización para posteriormente contrastar esta información con las áreas seleccionadas como objeto de estudio. Asimismo, se incluye información del perfil del egresado propuesto por cada institución educativa, con el fin de contrastar dicho perfil con las habilidades seleccionadas.

Una vez obtenidos los datos procedentes de las encuestas y aquellos provenientes de los contenidos programáticos ofertados en las maestrías en contabilidad, se utilizó el instrumento de medición de las distancias euclidianas propuesto por Rahman, Perera y Ganeshanandam (1996) y posteriormente profundizado por Garrido, León y Zorio (2002) y por Rico y Díaz (2017) para la medición de divergencias en los procesos de convergencia a

5 Se seleccionaron estas tres universidades por ser en las cuales laboran actualmente los autores de la ponencia.

6 Se seleccionaron únicamente los programas de maestría, excluyendo especializaciones y doctorados, con el fin de facilitar la medición de las categorías objeto de estudio. 
normativa internacional para países. Esta metodología es una "herramienta estadística que consiste en comparar y asignar un parámetro numérico a las divergencias presentadas entre principios y tratamientos contables alternativos" (Rico y Díaz, 2017, p. 74), y se calcula de la siguiente manera:

$$
d(X, Y)=\left[\sum_{j=1}^{J}\left(X_{j}-y_{j}\right)\right]^{1 / 2}
$$

Para efectos de este trabajo, se adaptó el instrumento para medir divergencias entre las categorías objeto de estudio: áreas y habilidades de formación. Si las perspectivas de los estudiantes son similares a lo ofertado por las maestrías, hay coincidencia; de lo contrario, existiría una divergencia que se medirá de acuerdo con la función de las distancias.

\section{Desarrollo del tema}

Para comparar las percepciones que tienen los estudiantes de contaduría pública de la oferta educativa de los programas de maestría en contabilidad en el país, frente a lo que ofrecen, es importante observar los siguientes aspectos:

1. La concepción normativa de los programas de posgrado en Colombia, dado que puede existir una incidencia en la oferta académica y por consiguiente en las percepciones.

2. El comportamiento de los programas de educación superior en el área de interés durante los últimos años como consecuencia de la reglamentación y las percepciones.

3. La conceptualización de las áreas disciplinares y las habilidades que se espera sean abordadas en la formación posgradual.

El propósito de abarcar estos puntos es iniciar con una contextualización general de la normativa aplicable a los programas de posgrado en el país, para así poder entender el contexto legal que moldea la creación y promulgación de programas de maestría, delimitando el modelo académico 
que se ofrece por parte de las instituciones de educación superior. Una vez comprendido el sentido normativo, se pasa a hacer una caracterización del comportamiento de la oferta y la demanda de los programas de pregrado y posgrado en contabilidad durante los últimos años, de manera que se observe si existen diferencias sustanciales en el número de programas y el número de estudiantes matriculados entre ambos niveles de formación. Finalmente, se realiza una revisión literaria de los diferentes campos contables para de este modo, permitir la identificación de las categorías objeto de estudio. Lo anterior, permitirá una interpretación integral de los resultados de la medición de las distancias euclidianas entre las percepciones que tienen los estudiantes de contaduría pública de la oferta educativa de los programas de maestría en contabilidad en el país y lo que dichos programas realmente ofrecen.

\section{Concepción normativa de los programas de posgrado en Colombia}

La educación superior en Colombia está reglamentada por la Ley 30 de 1992 y contempla dentro de este tipo de educación a los programas de pregrado y posgrado. En su artículo 10, determina como posgrados las especializaciones, maestrías, doctorados y posdoctorados. Para estos tres últimos, la normativa denota a la investigación como fundamento y ámbito necesario de su actividad, con el fin de:

Ampliar y desarrollar los conocimientos para la solución de problemas disciplinarios, interdisciplinarios o profesionales y dotar a la persona de los instrumentos básicos que la habilitan como investigador en un área específica de las ciencias o de las tecnologías o que le permitan profundizar teórica y conceptualmente en un campo de la filosofía, de las humanidades y de las artes. (Ley 30, 1992).

Asimismo, los programas de posgrado deben propender por que exista una formación integral en torno a cuatro objetivos de acuerdo con el Decreto 1001 del 2006 del Ministerio de Educación Nacional: 
a) El desarrollo de competencias para afrontar críticamente la historia y el desarrollo presente de su ciencia y de su saber.

b) La construcción de un sistema de valores y conceptos, basados en el rigor científico y crítico, en el respeto a la verdad y la autonomía intelectual, reconociendo el aporte de los otros y ejerciendo un equilibrio entre la responsabilidad individual y social y el riesgo implícitos en su desarrollo profesional.

c) La comprensión del ser humano, la naturaleza y la sociedad como destinatarios de sus esfuerzos, asumiendo las implicaciones sociales, institucionales, éticas, políticas y económicas de su investigación.

d) El desarrollo de las aptitudes para comunicarse y argumentar idóneamente en el área específica de conocimiento y para comunicar los desarrollos de la ciencia a la sociedad.

Los programas de maestría pueden tener un enfoque de investigación o de profundización. El primero, tiene como fin desarrollar en la persona competencias que le permitan participar activamente en procesos de investigación que generen conocimiento. Mientras que, el segundo, en ahondar en un área de conocimiento, así como en el desarrollo de competencias que posibilitan la solución de problemas y el análisis de situaciones por medio del uso de metodologías, conocimientos y desarrollos de carácter científico, tecnológico y artístico (Ministerio de Educación Nacional, 2006).

\section{Comportamiento de los programas de educación superior en el área de contabilidad en Colombia}

De acuerdo con cifras del SNIES, hasta septiembre del 2018 había 213 programas activos de pregrado de contaduría pública en todo el país (ver Anexo 3) con un total de 205913 estudiantes matriculados (ver Anexo 4)

7 Incluyendo denominaciones similares como "Contaduría Internacional” y "Contaduría y Finanzas". 
(Ministerio de Educación Nacional, 2018). En este sentido, el crecimiento promedio anual en el número de programas ofertados ha sido de $33.71 \%$ desde el año 2010, con un crecimiento total de $752 \%$ entre 2010 y 2018 . Asimismo, el crecimiento promedio anual en el número de estudiantes matriculados en programas de contaduría pública ha sido de $5.43 \%$ desde el año 2010, con un crecimiento total de $42.41 \%$ entre 2010 y 2018. Lo anterior implica que en términos del cumplimiento de los objetivos del Plan Nacional Decenal de Educación 2016-2026, los programas de contaduría pública muestran un balance positivo en relación con las cifras presentadas.

Igualmente, para la misma fecha había 7 programas de maestría en contabilidad o áreas contables en el país (ver Anexo 5), con un total de 357 estudiantes matriculados (ver Anexo 6) (Ministerio de Educación Nacional, 2018). El crecimiento promedio anual en el número de programas ofertados ha sido de $38.54 \%$ desde el año 2010, con un crecimiento total de $600 \%$ entre 2010 y 2018. Asimismo, el crecimiento promedio anual en el número de estudiantes matriculados en programas de maestría en contabilidad ha sido de $93.72 \%$ desde el año 2010, con un crecimiento total de $3866.67 \%$ entre 2010 y 2018.

Sin embargo, pese a que tanto la oferta y demanda de los programas de pregrado como la de posgrado han crecido, al comparar las cifras, es evidente que existe una brecha significativa entre ambos niveles de formación, la cual se podría explicar en parte por la poca atención que se le ha brindado a la formación posgradual a nivel de políticas públicas.

\section{Conceptualización de las áreas disciplinares y las habilidades}

El estudio, análisis y la aplicación de los conceptos referentes a las unidades productoras de información contable ${ }^{8}$ pueden ostentar diversas intenciona-

8 Entendidas como las empresas con fines de lucro, entidades sin ánimo de lucro, personas naturales, entidades públicas o cualquier ente que produzca información que pueda ser utilizada con fines contables y financieros. 
lidades, además de la dimensión académica transversal a todas las posibles áreas de la contabilidad, por lo cual han surgido clasificaciones de la disciplina, como la utilizada por Cañibano (1988) denotando una separación entre la macrocontabilidad, entendida como una perspectiva creada a través de la abstracción contable de todas las unidades económicas. Por otra parte, la microcontabilidad, es la contabilidad de las unidades económicas que componen el sistema económico, siendo esta última categoría sobre la que se trabaja en el presente escrito bajo las siete agrupaciones mencionadas en la metodología.

Respecto al estudio formalizado de la disciplina contable, teoría contable, se encuentra un sumario de los fundamentos básicos y visiones metodológicas desde las cuales se concibe y pretende hacer una comprensión de la contabilidad, encontrándose el estudio y desarrollo de paradigmas (esquemas formales), programas (conjunto de ideas vinculadas mediante un método) y tradiciones de investigación (presuposiciones de aplicación a la investigación) (Cañibano, 1974).

La clasificación de la contabilidad reconocida por su uso externo o general, es aquella que tiene por objetivo la preparación y presentación de estados contables, siendo estos los que dan cuenta de la renta y la riqueza, conociéndose como contabilidad financiera (Cañibano, 1988); por otra parte, los tratamientos contables que tienden a proveer datos e información a los agentes internos encargados de la gestión y la toma de decisiones dentro de la empresa se denominan contabilidad de gestión (Gómez, 2002), la cual ha mostrado una evolución moderada y constante en el estudio de los temas que se relacionan con esta (Facin, Queiro y Ripoll, 2008).

Asimismo, la mediación entre el sistema que permite la determinación de una base imponible para que el Gobierno, mediante el fisco, pueda cumplir con sus funciones y la producción de información financiera-económica para los inversionistas y la toma de decisiones, junto con todas las variaciones que se puedan presentar en esta área de estudio, se concibe como contabilidad impositiva (Aliwie y Adbullah, 2018; Sierra, 2008). De manera semejante, los sistemas y procedimientos que permiten la examinación y 
determinación de las actividades, técnicas y resultados enfocados en requerimientos legales o formales dentro de las organizaciones se identifican bajo los sistemas de control (Power y Terziovski, 2007; Saha y Roy, 2016).

Ahora bien, el conjunto de elementos que comprende el cuerpo normativo y el compendio técnico-práctico de las entidades y organismos públicos que manejan o administran recursos públicos y proporcionan información contable se denomina contabilidad gubernamental o contabilidad del sector público (Cañibano, 1988; Martínez, 2011). No obstante, mediante el entendimiento y comprensión de una realidad compleja, la apertura de los saberes disciplinares al entorno y la reciprocidad del conocimiento permite superar estancos del conocimiento y el distanciamiento de las construcciones teóricas y de las praxis (Ortiz, 2009), además de un desarrollo integrado para el abordaje y solución de problemas sociales significantes mediante un mejor acercamiento (O'Dwyer y Unerman, 2014), de tal manera que la unión de los conceptos contables con otros conocimientos como las finanzas, la economía, la administración, la biología y la psicología, entre otros, se encuentra bajo la denominación de líneas interdisciplinares.

En cuanto a las habilidades del profesional, se ha de tener en cuenta el entorno dinámico en el cual los profesionales contables desempeñan sus funciones. Por ello, se hace necesaria la circulación de los conocimientos y requerimientos respecto a la formación del profesional; en la cual, se presentan exigencias desligadas de los saberes técnico-contables y analítico-contables, donde Arquero (2000) resalta el rol de las habilidades de comunicación, el trabajo en grupo y la resolución de conflictos, destrezas sobre las cuales dicha investigación evidencia la percepción de deficiencias a nivel de oralidad y escritura. Por otra parte, Pietrzak y Wnuk-Pel (2015) mediante un estudio de los roles y cualidades del desempeño del profesional contable, describen la necesidad del desarrollo de habilidades relacionadas con la gestión de las organizaciones, así como la capacidad de explorar e inspeccionar temas de acuerdo con las necesidades organizacionales atendiendo a la mejora del desempeño y conocimiento en su conjunto. 
Por otro lado, Bui y Porter (2010) a través de un estudio realizado sobre las expectativas del desempeño de los profesionales contables, con énfasis en la educación que estos han recibido, describen fallas de las universidades para proveer y evaluar a los estudiantes holísticamente, denotando que las diferencias entre las expectativas se centraban sobre las competencias profesionales de los contadores y aptitudes en relación con las tareas a desarrollar por parte del profesional que integre el pensamiento contable en temas fundamentales como principios y conceptos, al igual que falencia en las capacidades interpersonales.

\section{Resultados}

En la Tabla 1 se muestran los resultados de las encuestas aplicadas a los estudiantes de pregrado únicamente para las preguntas que se utilizaron como base conceptual para el cálculo de las distancias. En esta tabla se divide el análisis en áreas y habilidades de formación. Para cada una de las áreas y habilidades propuestas se muestra el porcentaje de encuestados en donde se puede observar que, en cuanto a las áreas de formación, los estudiantes de pregrado tienen la expectativa de profundizar sus conocimientos mayoritariamente en contabilidad impositiva y sistemas de control, con 56 estudiantes para cada una de las áreas, lo cual corresponde al $51.14 \%$ de los encuestados. Asimismo, en cuanto a las habilidades, los estudiantes de pregrado tienen la expectativa de recibir formación enfocada mayoritariamente en el dominio de técnicas avanzadas sobre áreas particulares de la contabilidad y en el desarrollo del pensamiento contable con énfasis en áreas particulares de la contabilidad, con 100 y 86 estudiantes respectivamente, lo cual corresponde al $80.52 \%$ de los encuestados.

En contraste, las áreas sobre las cuales los estudiantes esperan formarse en maestría de menor interés son teoría contable, contabilidad gubernamental y contabilidad estratégica, con 3, 18 y 26 estudiantes respectivamente, lo cual corresponde al $21.46 \%$ de los encuestados. Igualmente, las habilidades de menor interés son el desarrollo de aptitudes de investigación formal y 
desarrollo de capacidades interpersonales y de comunicación, con 22 y 23 estudiantes respectivamente, lo cual corresponde al $19.48 \%$.

\section{Tabla 1. Expectativas de estudiantes de pregrado sobre los programas de maestría}

\begin{tabular}{l|c|c}
\hline $\begin{array}{l}\text { Cuáles son las áreas sobre las que espera formarse } \\
\text { en la maestría }\end{array}$ & Total & Porcentaje \\
\hline $\begin{array}{l}\text { Contabilidad estratégica (gestión, presupuestos y } \\
\text { proyectos) }\end{array}$ & 26 & 11.87 \\
\hline $\begin{array}{l}\text { Contabilidad financiera (contabilidad para usos externos } \\
\text { generales) }\end{array}$ & 33 & 15.07 \\
\hline $\begin{array}{l}\text { Contabilidad gubernamental (ámbitos de aplicación, } \\
\text { finanzas públicas) }\end{array}$ & 18 & 8.22 \\
\hline $\begin{array}{l}\text { Contabilidad impositiva (planeación, gestión y adminis- } \\
\text { tración tributaria) }\end{array}$ & 56 & 25.57 \\
\hline $\begin{array}{l}\text { Líneas interdisciplinares (ambiental, finanzas, psicología } \\
\text { y otras) }\end{array}$ & 27 & 12.33 \\
\hline $\begin{array}{l}\text { Sistemas de control (auditoría, control interno, asegura- } \\
\text { miento y cumplimiento) }\end{array}$ & 56 & 25.57 \\
\hline $\begin{array}{l}\text { Teoría contable (perspectivas, escuelas, modelos y } \\
\text { regulación) }\end{array}$ & 3 & 1.37 \\
\hline Total & $\mathbf{2 1 9}$ & \\
\hline
\end{tabular}

\begin{tabular}{l|c|c}
\hline $\begin{array}{l}\text { Cuáles son las habilidades que espera desarrollar en } \\
\text { su formación. }\end{array}$ & Total & Porcentaje \\
\hline Desarrollo de aptitudes de investigación formal. & 22 & 9.52 \\
\hline $\begin{array}{l}\text { Desarrollo de capacidades interpersonales y de } \\
\text { comunicación. }\end{array}$ & 23 & 9.96 \\
\hline $\begin{array}{l}\text { Desarrollo del pensamiento contable con énfasis áreas } \\
\text { particulares de la contabilidad. }\end{array}$ & 86 & 37.23 \\
\hline $\begin{array}{l}\text { Dominio de técnicas avanzadas sobre áreas particulares de } \\
\text { la contabilidad. }\end{array}$ & 100 & 43.29 \\
\hline Total & $\mathbf{2 3 1}$ & \\
\hline
\end{tabular}

Fuente: elaboración propia con base en los resultados de la encuesta aplicada. 
En la Tabla 2 se muestran los contenidos de los programas de maestría en contabilidad ofertados en el país. Para codificar los resultados, se utilizó en número 1 cuando un programa particular tuviese incorporado en su currículo el área o la habilidad específica, y 0 en el caso contrario. Se puede observar que, en cuanto a las áreas de formación, todos los programas de maestría en contabilidad ofertados en el país ofertan contabilidad estratégica y contabilidad financiera. Asimismo, en cuanto a las habilidades, las que más se repiten en los perfiles de egresados son el desarrollo del pensamiento contable con énfasis en áreas particulares de la contabilidad y el desarrollo de aptitudes de investigación formal, con 85.71 \% y $71.43 \%$ de los programas de maestría, respectivamente.

Por otro lado, el área de formación que se oferta en menor medida entre los programas de maestría en contabilidad es contabilidad gubernamental, donde únicamente la Universidad Libre la incluye en sus contenidos programáticos. Igualmente, la habilidad que se incluye en los perfiles de egresados en menor medida es el desarrollo de las capacidades interpersonales y de comunicación, con $28.57 \%$ del total de perfiles. 


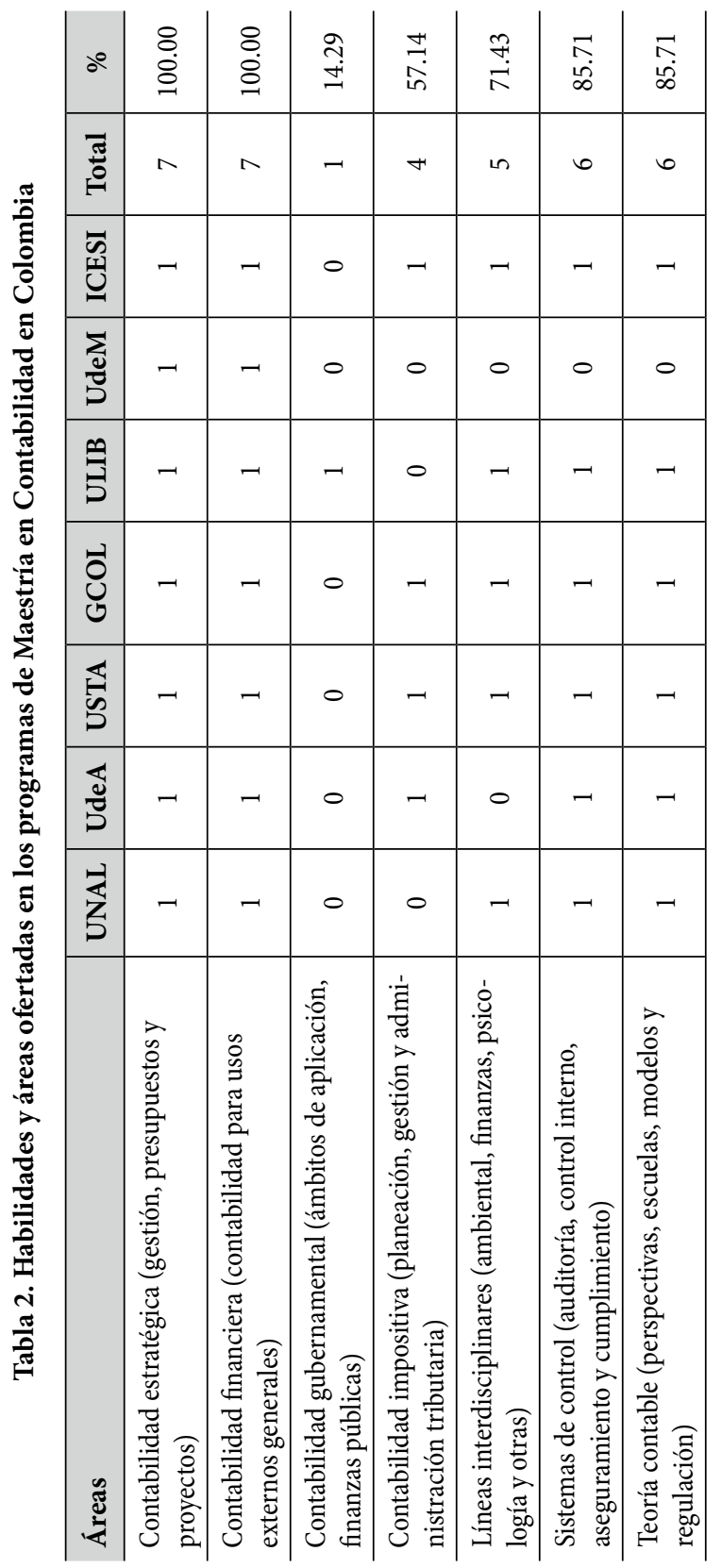


174 ACTivos | Paula Andrea Navarro Pérez, Laura Natalia Pulgarín García, Julián David Sandoval Alarcón

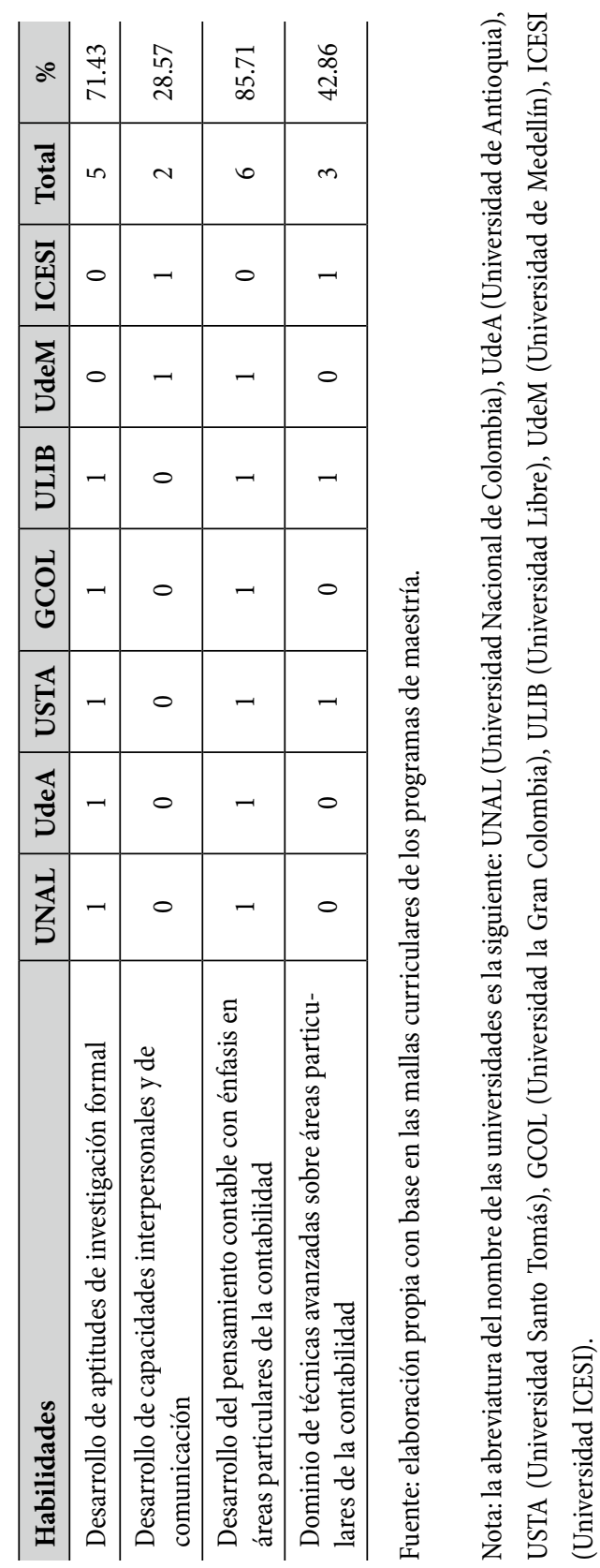


En la Tabla 3 se observa el cálculo de la distancia euclidiana entre las percepciones de los estudiantes de pregrado sobre los programas de maestría en contabilidad y lo que realmente ofrecen dichos programas. Se puede observar que existe mayor divergencia entre las áreas de formación que entre las habilidades. Las áreas que más distan entre la expectativa y la oferta son la contabilidad estratégica, la contabilidad financiera y la teoría contable, las cuales son ofertadas en la mayoría de los programas; pero no son consideradas relevantes por los estudiantes. Igualmente, la habilidad que más dista entre la expectativa y la oferta es el desarrollo de aptitudes de investigación formal. 
176 ACTIVOS | Paula Andrea Navarro Pérez, Laura Natalia Pulgarín García, Julián David Sandoval Alarcón

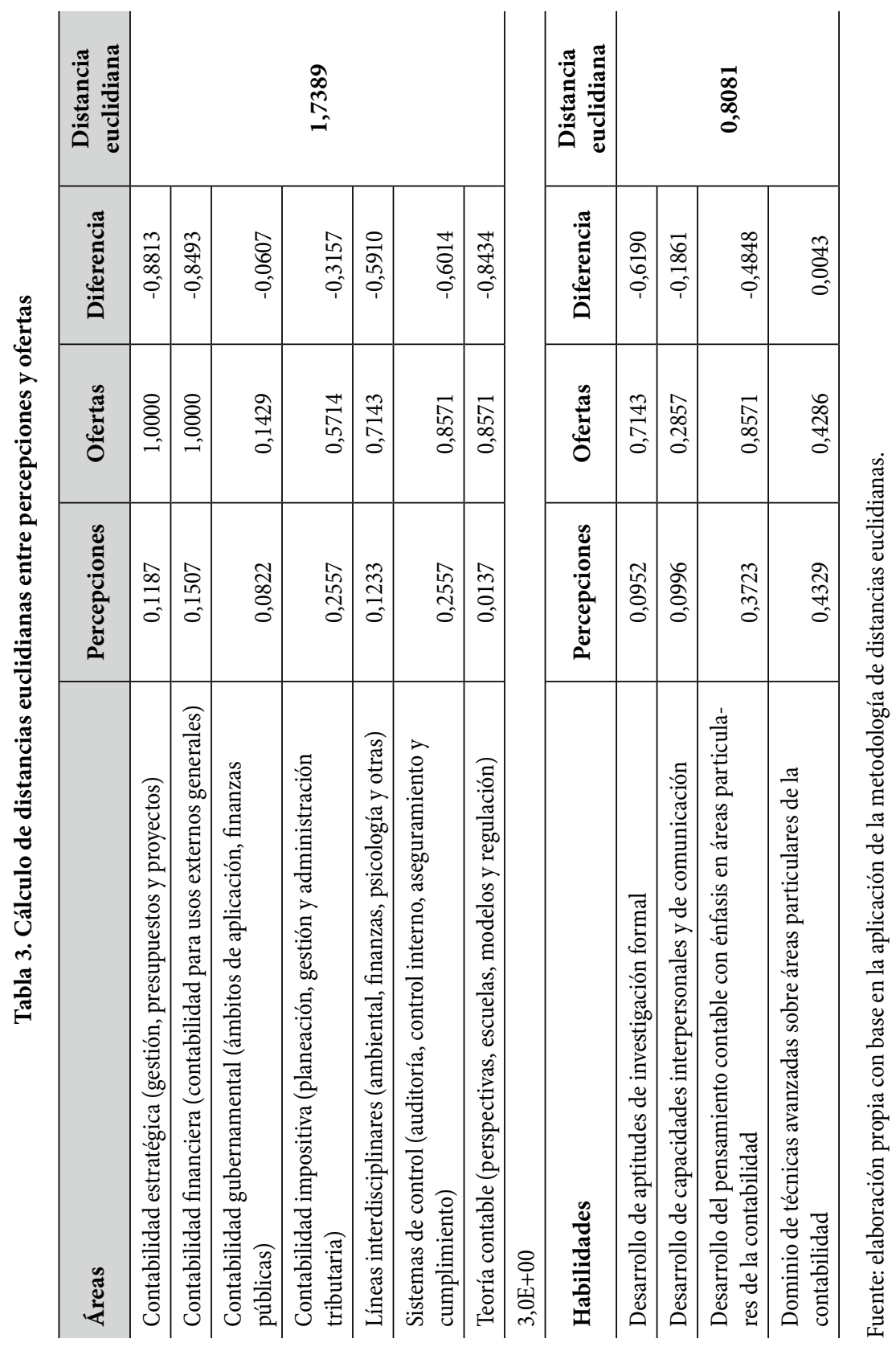




\section{Discusión y conclusiones}

Existen divergencias significativas entre las percepciones de los estudiantes de pregrado de contaduría pública y la oferta curricular de los programas de maestría en contabilidad, las cuales se pueden observar en los resultados. Las áreas de formación maestral de mayor interés para los estudiantes de pregrado son la contabilidad impositiva y sistemas de control; mientras que teoría contable, contabilidad estratégica y contabilidad gubernamental son las que menos interés tienen para los encuestados. En contraste, las áreas mayoritariamente ofertadas en los programas de maestría en contabilidad son contabilidad estratégica y contabilidad financiera; mientras que contabilidad gubernamental es la que menos se oferta.

En cuanto a las habilidades de formación, los encuestados mostraron mayor interés en las técnicas avanzadas sobre áreas particulares y el desarrollo del pensamiento contable; mientras que el desarrollo de aptitudes de investigación y el desarrollo de capacidades interpersonales y de formación son las de menor interés. Por su parte, las habilidades de mayor oferta en los programas de maestría en contabilidad son el desarrollo de aptitudes de investigación y el desarrollo del pensamiento contable; mientras que la de menor oferta es el desarrollo de capacidades interpersonales y de comunicación.

De acuerdo con lo anterior, es evidente que para algunas áreas y habilidades de formación existen disparidades entre la oferta y la demanda, lo cual en principio supondría un valor significativo en las distancias euclidianas. Estas distancias están ocasionadas por la poca coincidencia tanto en la mayoría de las áreas como en la mayoría de las habilidades, lo cual podría ser explicado por un desconocimiento de los estudiantes de pregrado sobre las ofertas específicas de posgrado o por un desconocimiento de las instituciones de educación superior sobre las expectativas de los estudiantes de pregrado; sin embargo, es necesario adelantar estudios adicionales que permitan identificar con certeza las razones de las divergencias presentadas. 
Adicionalmente, como se infiere del análisis de los planes de estudio de los programas, el elemento diferenciador entre el nivel posgradual de especialización y maestría es la línea de investigación formalizada dentro de los programas. Sin embargo, esta no es una clara expectativa que tengan los estudiantes de pregrado respecto a la maestría, lo cual indica que posiblemente la formación de pregrado requiere mayor énfasis en investigación y desarrollo del pensamiento investigativo, razón por la cual los estudiantes no consideran estos elementos relevantes aun cuando todos los programas de maestría en contabilidad los tienen como un componente fundamental en el proceso formativo.

Por último, este estudio es parte del inicio de una línea de investigación enfocada en la formación posgradual en contabilidad que posibilite articular los esfuerzos literarios hechos anteriormente dirigidos a los programas de pregrado con el auge de los procesos formativos posgraduales en Colombia y que permita mejorar el flujo de información entre el ciclo educativo, donde se conozcan las expectativas en cualquier nivel de formación y estas, a su vez, sean recogidas en la construcción y formalización de los programas.

\section{Referencias}

Aliwie, N., y Adbullah, Q. (2018). The impact of international taxation systems variations on the application of financial accounting principles. Academy of Accounting and Financial Studies Journal, 22(2), 1-11. Recuperado de https:// www.researchgate.net/publication/324970568

Araújo, J. A. (2000). Educación superior y contaduría pública. Revista Internacional de Contabilidad \& Auditoría Legis, (2).

Ariza, D. (2003). La interdisciplinariedad contable como mecanismo de su supervivencia social. Revista Cuadernos de Administración, (28). Facultad de Ciencias de la Administración. Universidad del Valle.

Ariza, E., y Soler, E. (2004). La crisis de la universidad. ¿Una lección para reconstruir el tránsito disciplinar de la contabilidad en Colombia? Lúmina, (5), 171-194. Recuperado de file:///C:/Users/Usuario/Downloads/1160-Texto\%20del\%20ar t\%C3\%ADculo-4811-1-10-20151028.pdf 
Arquero, J. L. (2000). Capacidades no técnicas en el perfil profesional en contabilidad: las opiniones de docentes y profesionales. Revista Española de Financiación y Contabilidad, 29(103), 149-172. Recuperado de file://C:/ Users/Usuario/Downloads/Dialnet-CapacidadesNoTecnicasEnElPerfilProfe sionalEnContab-44340.pdf

Barragán, D. M. (2009). Currículum en Contaduría Pública: una visión panorámica de un fenómeno complejo. Trabajo presentado en el I Encuentro Nacional de Profesores de Contaduría Pública. Pontificia Universidad Javeriana, Bogotá D. C., Colombia.

Bui, B., y Porter, B. (2010). The expectation-performance gap in accounting education: an exploratory study. Accounting Education: an international journal, 19(1-2), 23-50. DOI: 10.1080/09639280902875556

Cañibano, L. (1974). El concepto de la contabilidad como programa de investigación. Revista Española de Financiación y Contabilidad, 3(7), 33-45.

Cañibano, L. (1988). Contabilidad. Análisis contable de la realidad económica. Madrid, España: Ediciones Pirámide.

Cárdenas-Londoño, R. (2009). Papel de las metodologías de enseñanza del proceso lectoescritural en la educación superior. Cuadernos de Contabilidad, 10(26), 87-109.

Cardona, J. (1998). Reflexiones en torno a la relación docencia-investigación en materia contable. Contaduría Universidad de Antioquia, (32), 37-53

Castillo, C., Córdoba, J., y Villareal, J. (2014). Estándares internacionales de educación (IES) en contabilidad y aseguramiento: nuevos retos de la profesión contable. Tendencias, 15(2), 118-135.

Cerón, H. (2012). Estudio de la oferta académica de maestrías en contabilidad en América Latina. Revista Internacional de Contabilidad \& Auditoría Legis, (51), 71-100.

Crawford, D. (2017). Factors influencing the likelihood of developing a master's degree in accounting at U.S. AACSB business schools. Academy of Accounting and Financial Studies Journal, 21(2), 1-18.

Facin, C., Queiro, C., y Ripoll, V. (2008). Impacto de los artículos publicados en contabilidad de gestión. Universo Contábil, 4(3), 95-110. Recuperado de http:// www.redalyc.org/articulo.oa?id=117016815007 
Garrido, P., León, A., y Zorio, A. (2002). Measurement of formal harmonization progress: The IASC experience. The International Journal of Accounting, 37(1), $1-26$.

Giraldo, X. (2013). Contabilidad y diversidad cultural: apuntes para pensar un proyecto educativo en contaduría. En Memorias III Encuentro Nacional de Profesores de Contaduría Pública. Desarrollos y desafíos de la educación contable en Colombia. Cali: Pontificia Universidad Javeriana y Universidad del Valle.

Gómez, C. (2002). La economía institucionalista y la contabilidad de gestión. Análisis Económico, 17(35), 79-92. Recuperado de http://www.redalyc.org/ articulo.. a? id $=41303503$

Gómez, M. (2007). Las insuficiencias disciplinares de los estándares internacionales de educación -IES- para contadores profesionales. Lúmina, (8), 24-42.

Gómez, M. (2016). Breve introducción al estado del arte de la orientación crítica en la disciplina contable. Contaduría Universidad de Antioquia, (45), 113-132.

Hernández Campos, A., Tamez Garza, S., Leal Martínez, J. L., y Garza Coronado, J. L. (2013). Expectativas de los estudiantes de primer ingreso en la Maestría en Contaduría: Caso FACPYA. Innovaciones de Negocios, 10(20), 241-249. Recuperado de file://C:/Users/Usuario/Downloads/120-228-1-SM.pdf

Herrera, F. (2013). Los dilemas morales como estrategia pedagógica para la formación ética del contador público. En Memorias III Encuentro Nacional de Profesores de Contaduría Pública. Desarrollos y desafíos de la educación contable en Colombia. Cali, Pontificia Universidad Javeriana y Universidad del Valle.

Jaramillo Salazar, H. (2009). La formación de posgrado en Colombia. Revista Iberoamericana de Ciencia, Tecnología y Sociedad, 5(13), 131-155. Recuperado de file:///C:/Users/Usuario/Downloads/art\%C3\%ADculo_redalyc_92415269008.pdf

Ley 30. (1992). Por la cual se organiza el servicio público de la educación superior. Diario Oficial n. ${ }^{\circ} 40.700$ de la República de Colombia, Bogotá D. C., Colombia, diciembre 28 de 1992.

Loaiza, F. (2013). Corrientes educativas internacionales presentes en programas de contaduría pública. Cuadernos de Contabilidad, 14(34), 189-215.

Martínez, A. (2011). Una doble calzada: la técnica contable y la didáctica creativa. Nueva lógica de posibilidades pensada desde las sensaciones hasta las razones. 
En Memorias II Encuentro de Profesores de Contaduría Pública. Bogotá D. C. Universidad Nacional de Colombia y Universidad Santo Tomás.

Ministerio de Educación Nacional - MEN. (2006). Decreto 1001 de 2006. Por el cual se organiza la oferta de programas de posgrado y se dictan otras disposiciones. Bogotá D. C., Colombia.

Ministerio de Educación Nacional - MEN. (2016). Plan Decenal Nacional de Educación 2016-2026. Bogotá D. C., Colombia.

Ministerio de Educación Nacional - MEN. (2018). Estadísticas. Sistema Nacional de Información de la Educación Superior. Bogotá D. C., Colombia.

O’Dwyer, B., y Unerman, J. (2014). Realizing the potential of interdisciplinarity in accounting research. Accounting, Auditing \& Accountability Journal, 27(8), 1227-1232. DOI: https://doi.org/10.1108/AAAJ-07-2014-1756

Ortiz, J. (2009). Fronteras de la investigación contable-financiera-económica: autonomía e interdisciplinariedad. Revista Facultad de Ciencias Económicas: Investigación y Reflexión, 17(1), 179-194. Recuperado de http://www.redalyc. org/articulo.oa?id=90913041010

Ospina, C. (2016). Las tramas de la contabilidad: trazos para quienes empiezan su formación en contaduría pública. Contaduría Universidad de Antioquia, (48), 155-186.

Patiño, R., y Santos, G. (2009). Plan de estudios de Contaduría Pública en Colombia y propuestas de formación profesional. Revista Internacional de Contabilidad \& Auditoría Legis, (37), 131-164.

Patiño, R., Valero, G., Acosta, M., Parra, J., y Bautista, J. (2016). Revisión de literatura sobre educación contable en Colombia. Activos, 14(26), 61-99. Recuperado de https://revistas.usantotomas.edu.co/index.php/activos/article/ viewFile/3972/3799

Pietrzak, Z., y Wnuk-Pel, T. (2015). The roles and qualities of management accountants in organizations - evidence from the field. Procedia -Social and Behavioral Sciences, (213), 281-285. DOI: 10.1016/j.sbspro.2015.11.538

Power, D., y Terziovski, M. (2007). Quality audit roles and skills: Perceptions of non-financial auditors and their clients. Journal of Operations Management, 126-147. DOI: 10.1016/j.jom.2006.02.005 
Rahman, A., Perera, H., y Ganeshanandam, S. (1996). Measurement of formal harmonisation in accounting: an exploratory study. Accounting and Business Research, 26(4), 325-339.

Rico, C. y Díaz, M. (2017). ¿Convergencia de la regulación contable colombiana para las entidades de gobierno con las International Public Sector Accounting Standards (IPSAS)? Una medición de la armonización formal. Contabilidad y Negocios, 12(24), 61-83. Recuperado de https://www.redalyc.org/ pdf/2816/281655057005.pdf

Rodríguez-Castro, B. (2010). Retos de la academia contable. Cuadernos de Contabilidad, 11(28), 11-13.

Sánchez, W. (2011). Valores contables: competencias socioafectivas para contaduría pública. Armenia, Colombia: Investigar Editores.

Saha, S., y Roy, M. (2016). Quality Control Framework for Statutory Audit of Financial Statements: A Comparative Study of USA, UK and India. Indian Journal of Corporate Governance, 9(2), 186-211. DOI: 10.1177/0974686216668458.

Sierra, E. (2008). Análisis de la relación entre contabilidad y fiscalidad en Colombia. INNOVAR. Revista de Ciencias Administrativas y Sociales, 18(31), 117-134. Recuperado de http://www.redalyc.org/articulo.oa?id=81803110

Tua, J. (1995). Algunas implicaciones del paradigma de utilidad en la disciplina contable. Contaduría Universidad de Antioquia, (16), 17-50.

Vásquez-Bernal, R. (2002). Nuevos desafíos de la educación frente a estándares internacionales de formación en contaduría pública. Cuadernos de Contabilidad, (19), 151-156.

Villareal, J., Martínez, J., y Muñoz, C. (2016). De la educación contable internacional al desarrollo de competencias. Revista Espacios, 37(33).

Zapata, M. (1998). Paradojas en las propuestas de rediseño curricular. Lúmina, (2), 71-87. 


\section{Anexos}

\section{Anexo 1. Encuesta y resultados}

Sexo

259 respuestas

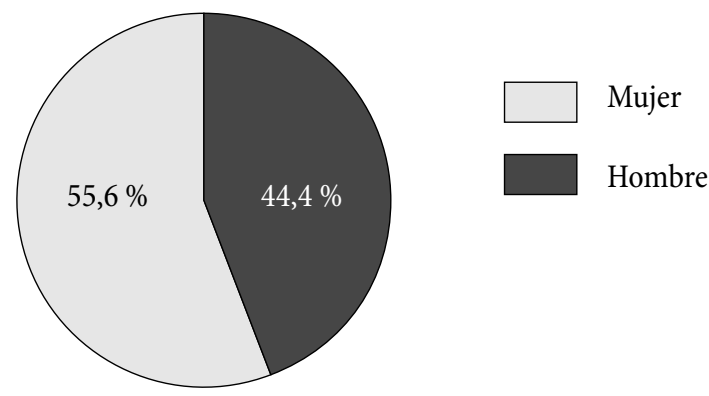

Actualmente trabaja en labores contables

259 respuestas

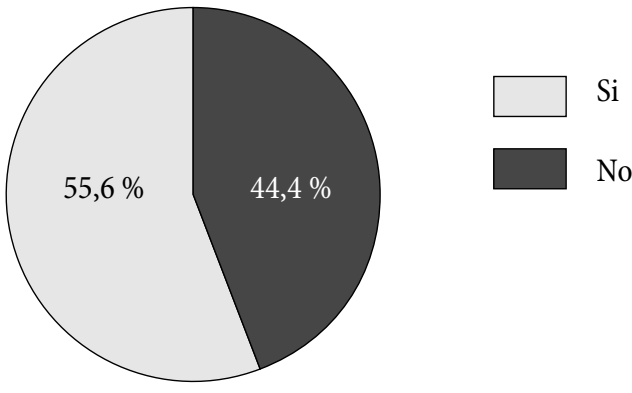


184 ACTIVOS | Paula Andrea Navarro Pérez, Laura Natalia Pulgarín García, Julián David Sandoval Alarcón

\section{Actualmente se encuetra cursando}

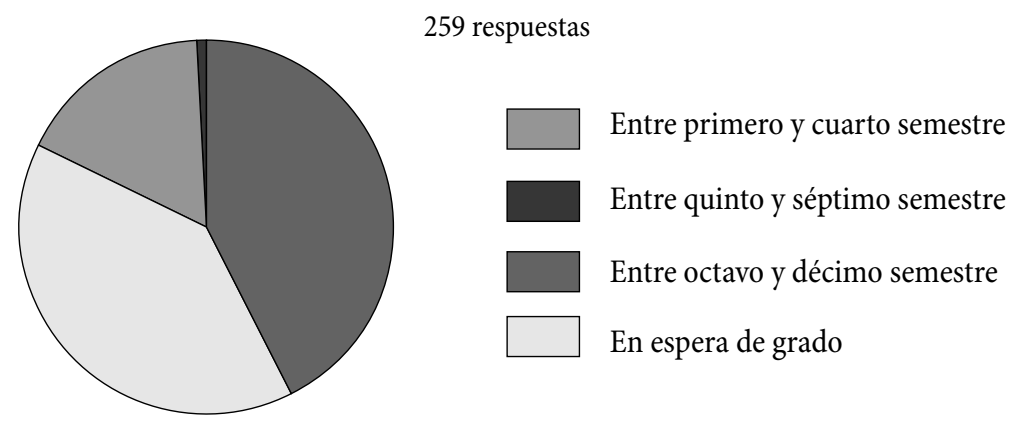

Se ha planteado usted realizar una maestría en Contabilidad

259 respuestas

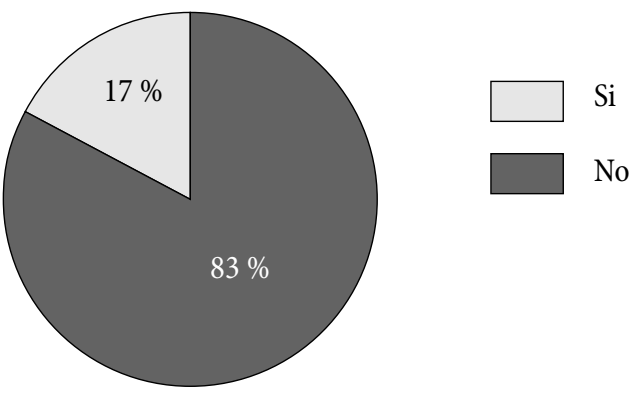

Si su respuesta fue NO, identifique la razón de su elección

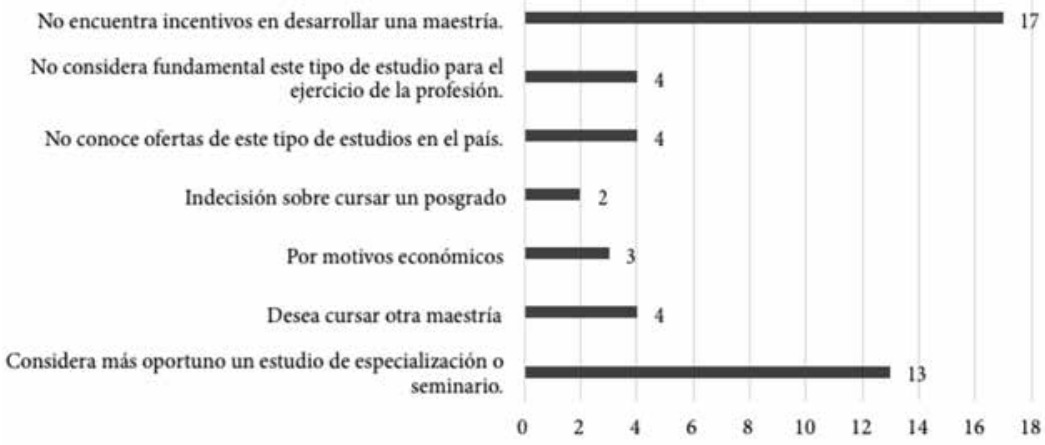

Universidad Santo Tomás, Facultad de Contaduría Pública 


\section{Cuáles son las áreas sobre las que espera formarse en la maestría}

238 respuestas
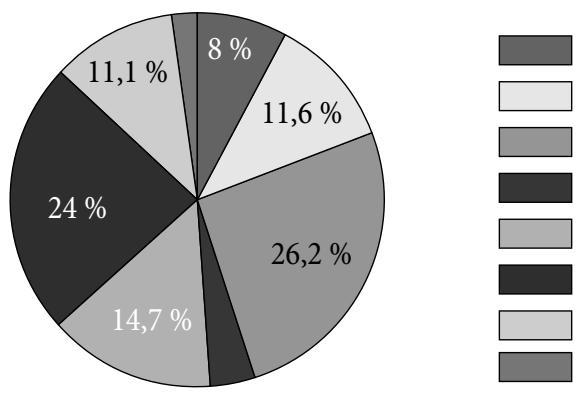

Contabilidad gubernamental Líneas interdisciplinares Sistemas de control En educación superior Contabilidad financiera Contabilidad impositiva Contabilidad estratégica Teoría contable

\section{Cuál son las habilidades que espera desarrollar en su formación}

\section{8 respuestas}

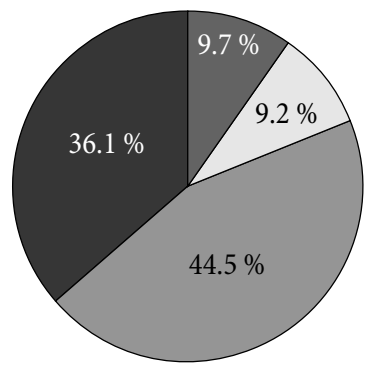

Desarrollo del pensamiento contable con énfasis áreas particulares de la contabilidad

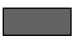
Desarrollo de capacidades interpersonales y de comunicación

$\square$ Desarrollo de aptitudes de investigación formal

$\square$ Dominio de técnicas avanzadas sobre áreas particulares de la contabilida

\section{Cuál es la motivación para cursar una maestría en contabilidad}

235 respuestas

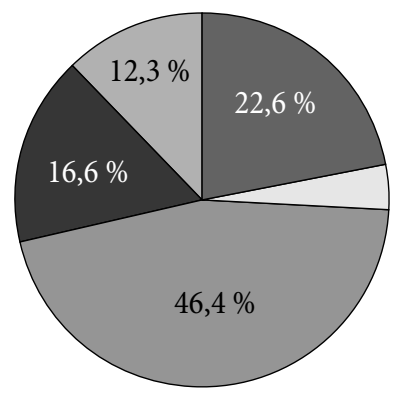

Mejora de las condiciones salariales

Mejora del acceso a convocatorias

Gusto personal (motivaciones de...)

La investigación contable teórica

Todas las anteriores

Todo lo anterior

Crecer profesionalmente y person...

No puedo decir que hay una única...

Desarrollo continuo de las competencias profesionales 
Anexo 2. Mallas curriculares Maestrías en Contabilidad

UNIVERSIDAD NACIONAL DE COLOMBIA ${ }^{9}$

Programa: Maestría en Contabilidad y Finanzas

Título: Magíster en Contabilidad y Finanzas

\section{Perfil del egresado:}

\section{Plan de profundización}

El egresado de la Maestría en Contabilidad y Finanzas será una persona que posee las capacidades académicas necesarias para aplicar los avances teóricos a la solución de problemas colombianos y países vecinos. Tendrá la capacidad para comprender el comportamiento empresarial en términos de los sistemas de información, de control y de las decisiones de inversión y financiación. Se espera de él que incorpore el aprendizaje en estas materias para diseñar y agenciar nuevas alternativas instrumentales que mejoren el desarrollo empresarial. Considerando que dispondrá de los conocimientos teóricos que le permitirán aproximarse a la comprensión de los mercados de capitales, se desea que lidere el desarrollo de mecanismos que eviten crisis o procesos especulativos que afecten el adecuado desempeño empresarial y de los mercados.

\section{Plan de investigación}

El futuro investigador dispondrá de las habilidades para integrar desarrollos disciplinarios diferentes y experiencias colombianas propias para producir nuevo conocimiento sobre: la teoría de la contabilidad, el control, las finanzas y los mercados de capitales. De hecho, el egresado contará con un enriquecimiento disciplinar que potenciará su desempeño pedagógico y metodológico en la docencia. A la vez, gozará de capacidades y fundamentación

9 Información tomada de la página web de la Facultad de Ciencias Económicas de la Universidad Nacional de Colombia. 
conceptual e instrumental para identificar y abordar problemas contables sociales y contextuales, potenciando el desarrollo disciplinar para el tratamiento de asuntos críticos en las organizaciones

\section{Plan de estudios:}

Plan de profundización

\begin{tabular}{c|c}
\hline Estructura & Créditos \\
\hline Actividades académicas & \\
\hline Tesis & 25 \\
\hline Proyecto de tesis & 3 \\
\hline Seminarios de investigación & 8 \\
\hline SUBTOTAL & $\mathbf{3 6}$ \\
\hline Asignaturas elegibles & 24 \\
\hline TOTAL & $\mathbf{6 0}$ \\
\hline
\end{tabular}

\begin{tabular}{|c|c|c|}
\hline Área de profundización & Asignatura & Créditos \\
\hline \multicolumn{3}{|l|}{ PRIMER SEMESTRE } \\
\hline \multirow{4}{*}{ Contabilidad } & Teorías y modelos contables & 4 \\
\hline & Regulación contable & 4 \\
\hline & Asignatura obligatoria I (línea de control) & 4 \\
\hline & Asignatura obligatoria I (línea de finanzas) & 4 \\
\hline \multirow{4}{*}{ Control } & Aseguramiento de la información financiera & 4 \\
\hline & Estructura regulatoria del aseguramiento & 4 \\
\hline & Asignatura obligatoria I (línea de contabilidad) & 4 \\
\hline & Asignatura obligatoria I (línea de finanzas) & 4 \\
\hline \multirow{4}{*}{ Finanzas } & Economía financiera & 4 \\
\hline & Inversiones & 4 \\
\hline & Asignatura obligatoria I (línea de contabilidad) & 4 \\
\hline & Asignatura obligatoria I (línea de control) & 4 \\
\hline
\end{tabular}




\begin{tabular}{l|l|l}
\hline \multicolumn{2}{l}{ SEGUNDO SEMESTRE } & \multicolumn{2}{|l}{} & 4 \\
\hline \multirow{4}{*}{$\begin{array}{l}\text { Contabilidad - Control } \\
\text { - Finanzas }\end{array}$} & Seminario de investigación I & 4 \\
\cline { 2 - 3 } & Asignatura electiva & 4 \\
\cline { 2 - 3 } & Asignatura electiva & 4 \\
\cline { 2 - 3 } & Asignatura electiva & 3 \\
\hline TERCER SEMESTRE & Propuesta de trabajo final & 4 \\
\cline { 2 - 3 } & Asignatura electiva & 4 \\
\cline { 2 - 3 } $\begin{array}{l}\text { Contabilidad - Control } \\
\text { - Finanzas }\end{array}$ & Asignatura electiva & 4 \\
\cline { 2 - 3 } & Asignatura electiva & 4 \\
\hline CUARTO SEMESTRE & Asignatura electiva & 6 \\
\hline Contabilidad - Control & Trabajo final & 60 \\
\hline - Finanzas & & \multicolumn{2}{|l}{} \\
\hline Total & &
\end{tabular}

Asignaturas de las electivas por área:

- Contabilidad: contabilidad financiera, contabilidad de gestión, teoría y pensamiento contable.

- Control: gobernabilidad corporativa, procesos de aseguramiento, medición del desempeño en mipymes, ética y responsabilidad social.

- Finanzas: finanzas corporativas, riesgo y valoración, métodos cuantitativos, mercados financieros.

\section{Plan de investigación}

\begin{tabular}{l|c}
\hline Estructura & Créditos \\
\hline Actividades académicas & \\
\hline Trabajo final & 9 \\
\hline Propuesta de trabajo final & 3 \\
\hline Seminarios de investigación & 4 \\
\hline Subtotal & 16 \\
\hline
\end{tabular}




\begin{tabular}{l|c}
\hline Estructura & Créditos \\
\hline Asignaturas obligatorias & 16 \\
\hline Asignaturas elegibles & 28 \\
\hline Total & $\mathbf{6 0}$ \\
\hline
\end{tabular}

\begin{tabular}{|c|c|}
\hline Asignatura & Créditos \\
\hline \multicolumn{2}{|l|}{ PRIMER SEMESTRE } \\
\hline Seminario de investigación I & 4 \\
\hline Asignatura electiva & 4 \\
\hline Asignatura electiva & 4 \\
\hline Asignatura electiva & 4 \\
\hline \multicolumn{2}{|l|}{ SEGUNDO SEMESTRE } \\
\hline Seminario de investigación I & 4 \\
\hline Proyecto de tesis & 3 \\
\hline Asignatura electiva & 4 \\
\hline \multicolumn{2}{|l|}{ TERCER SEMESTRE } \\
\hline Asignatura electiva & 4 \\
\hline Asignatura electiva & 4 \\
\hline \multicolumn{2}{|l|}{ CUARTO SEMESTRE } \\
\hline Tesis & 25 \\
\hline Total & 60 \\
\hline
\end{tabular}

Asignaturas de las electivas por área:

- Contabilidad: contabilidad financiera, contabilidad de gestión, teoría y pensamiento contable.

- Control: gobernabilidad corporativa, procesos de aseguramiento, medición del desempeño en mipymes, ética y responsabilidad social.

- Finanzas: finanzas corporativas, riesgo y valoración, métodos cuantitativos, mercados financieros. 


\section{UNIVERSIDAD DE ANTIOQUÍA ${ }^{10}$}

Programa: Maestría en Ciencias Contables

Título: Magíster en Ciencias Contables

\section{Perfil del egresado:}

El egresado estará en capacidad de desarrollar un pensamiento analítico y crítico que le permita comprender las bases conceptuales, teóricas, metodológicas y técnicas que desde la contabilidad orienta las actividades de planificación, gestión, dirección y evaluación de los recursos, de manejo eficiente de los sistemas de información contable, del desarrollo de procesos de control organizacional (auditorías, revisoría fiscal y control interno), de los procesos de armonización contable y del desarrollo investigativo en un contexto global.

\section{Plan de estudios:}

\begin{tabular}{|c|c|c|c|c|}
\hline & I Semestre & II Semestre & III Semestre & IV Semestre \\
\hline \multirow{2}{*}{$\begin{array}{l}\text { Tronco } \\
\text { común }\end{array}$} & Teoría contable & Teoría del control & \multirow[b]{2}{*}{ Electiva I } & \multirow[b]{2}{*}{ Electiva II } \\
\hline & $\begin{array}{l}\text { Metodología de } \\
\text { la investigación }\end{array}$ & Contabilometría & & \\
\hline \multirow[t]{2}{*}{ Investigación } & $\begin{array}{l}\text { Asignatura } \\
\text { obligatoria de } \\
\text { acuerdo a la } \\
\text { línea temática }\end{array}$ & $\begin{array}{l}\text { Asignatura } \\
\text { obligatoria de } \\
\text { acuerdo a la línea } \\
\text { temática }\end{array}$ & $\begin{array}{l}\text { Asignatura } \\
\text { obligatoria de } \\
\text { acuerdo a la } \\
\text { línea temática }\end{array}$ & \multirow{2}{*}{$\begin{array}{l}\text { Trabajo de } \\
\text { investigación }\end{array}$} \\
\hline & $\begin{array}{l}\text { Evolución del } \\
\text { pensamiento } \\
\text { contable }\end{array}$ & $\begin{array}{l}\text { Seminario de } \\
\text { investigación I }\end{array}$ & $\begin{array}{l}\text { Seminario de } \\
\text { investigación II }\end{array}$ & \\
\hline
\end{tabular}

10 Información tomada de la página web de la Facultad de Ciencias Económicas de la Universidad de Antioquia. 


\begin{tabular}{|c|c|c|c|c|}
\hline \multirow{3}{*}{$\begin{array}{l}\text { Costos y } \\
\text { gestión }\end{array}$} & $\begin{array}{l}\text { Evolución de la } \\
\text { contabilidad de } \\
\text { gestión }\end{array}$ & Cálculo de costos & $\begin{array}{l}\text { Análisis de } \\
\text { costos y toma } \\
\text { de decisiones }\end{array}$ & \multirow{3}{*}{$\begin{array}{l}\text { Trabajo de } \\
\text { grado }\end{array}$} \\
\hline & $\begin{array}{l}\text { Consultorio } \\
\text { Contable I: } \\
\text { Diseño y me- } \\
\text { joramiento de } \\
\text { procesos }\end{array}$ & $\begin{array}{l}\text { Consultorio } \\
\text { Contable II: } \\
\text { Diseño de mode- } \\
\text { los de costos }\end{array}$ & $\begin{array}{l}\text { Consultorio } \\
\text { Contable III: } \\
\text { Uso de T.I en la } \\
\text { contabilidad de } \\
\text { gestión }\end{array}$ & \\
\hline & & & $\begin{array}{l}\text { Seminario de } \\
\text { investigación }\end{array}$ & \\
\hline \multirow{3}{*}{$\begin{array}{l}\text { Contabilidad } \\
\text { internacional }\end{array}$} & $\begin{array}{l}\text { Modelo } \\
\text { contable } \\
\text { internacional }\end{array}$ & $\begin{array}{l}\text { Estándares } \\
\text { internacionales } \\
\text { de la información } \\
\text { financiera I }\end{array}$ & $\begin{array}{l}\text { Estándares } \\
\text { internacionales } \\
\text { de la informa- } \\
\text { ción financiera } \\
\text { II }\end{array}$ & \multirow{3}{*}{$\begin{array}{l}\text { Trabajo de } \\
\text { grado }\end{array}$} \\
\hline & $\begin{array}{l}\text { Consultorio } \\
\text { Contable I: } \\
\text { Diagnóstico } \\
\text { organizacional }\end{array}$ & $\begin{array}{l}\text { Consultorio } \\
\text { Contable II: } \\
\text { Implementación } \\
\text { por primera vez } \\
\text { de los estándares } \\
\text { internacionales }\end{array}$ & $\begin{array}{l}\text { Consultorio } \\
\text { Contable III: } \\
\text { Aplicación } \\
\text { NIC-NIIF }\end{array}$ & \\
\hline & & & $\begin{array}{l}\text { Seminario de } \\
\text { Investigación }\end{array}$ & \\
\hline \multirow{3}{*}{ Tributaria } & $\begin{array}{l}\text { Régimen y } \\
\text { procedimiento } \\
\text { tributario }\end{array}$ & $\begin{array}{l}\text { Consultorio } \\
\text { Contable II: } \\
\text { Planeación y au- } \\
\text { ditoría tributaria }\end{array}$ & $\begin{array}{l}\text { Tributación } \\
\text { internacional } \\
\text { y precios de } \\
\text { transferencia }\end{array}$ & \multirow{3}{*}{$\begin{array}{l}\text { Trabajo de } \\
\text { grado }\end{array}$} \\
\hline & $\begin{array}{l}\text { Consultorio } \\
\text { Contable I: } \\
\text { Procedimiento } \\
\text { tributario }\end{array}$ & $\begin{array}{l}\text { Planeación y au- } \\
\text { ditoría tributaria }\end{array}$ & $\begin{array}{l}\text { Consultorio } \\
\text { Contable III: } \\
\text { Tributación } \\
\text { internacional } \\
\text { y precios de } \\
\text { transferencia }\end{array}$ & \\
\hline & & & $\begin{array}{l}\text { Seminario de } \\
\text { Investigación }\end{array}$ & \\
\hline
\end{tabular}




\begin{tabular}{|c|c|c|c|c|}
\hline \multirow{3}{*}{$\begin{array}{l}\text { Auditoría y } \\
\text { control }\end{array}$} & $\begin{array}{l}\text { Control interno } \\
\text { contable }\end{array}$ & $\begin{array}{l}\text { Control externo: } \\
\text { auditoría y revi- } \\
\text { soría fiscal }\end{array}$ & $\begin{array}{l}\text { Control } \\
\text { fiscal: auditoría } \\
\text { gubernamental }\end{array}$ & \multirow{3}{*}{$\begin{array}{l}\text { Trabajo de } \\
\text { grado }\end{array}$} \\
\hline & $\begin{array}{l}\text { Consultorio } \\
\text { Contable I: } \\
\text { Implementación } \\
\text { de modelos de } \\
\text { control interno }\end{array}$ & $\begin{array}{l}\text { Consultorio } \\
\text { Contable II: } \\
\text { Implementación } \\
\text { de las NIA }\end{array}$ & $\begin{array}{l}\text { Consultorio } \\
\text { Contable III: } \\
\text { Implementación } \\
\text { de modelos } \\
\text { de control } \\
\text { gubernamental }\end{array}$ & \\
\hline & & & $\begin{array}{l}\text { Seminario de } \\
\text { Investigación }\end{array}$ & \\
\hline
\end{tabular}

\section{UNIVERSIDAD SANTO TOMÁS ${ }^{11}$}

Programa: Maestría en Ciencias Contables

Título: Magíster en Ciencias Contables

\section{Perfil del egresado:}

El magíster en Ciencias Contables, egresado de la Universidad Santo Tomás, sede Bucaramanga, será un líder en normas internacionales de información financiera y en aseguramiento de la información y en planificación tributaria, con formación integral y visión global, proyección nacional e internacional, capaz de analizar la realidad social e identificar complejos procesos en un contexto globalizado, ser agente de cambio con enfoque interdisciplinario en las ciencias económicas, y generar soluciones en las organizaciones para la toma de decisiones en entornos cambiantes y complejos que implican una actitud de compromiso con la excelencia.

11 Información tomada de la página web de la Universidad Santo Tomás, sede Bucaramanga. 
De acuerdo con el pensamiento humanista de santo Tomás, el estudiante de la Maestría en Ciencias Contables de la Universidad Santo Tomás, investiga con un alto nivel reflexivo, crítico y con formación ética, para favorecer el desarrollo humano integral, produce conocimiento con relevancia científica, pertinencia y trascendencia social en el campo del área contable y financiera en el ámbito local, nacional o internacional, se vincula activamente a redes de colaboración y de innovación social para la aplicación del conocimiento de frontera.

\section{Plan de estudios:}

\begin{tabular}{|c|c|}
\hline \multicolumn{2}{|l|}{ PRIMER SEMESTRE } \\
\hline Asignatura & Créditos \\
\hline Inducción y Nivelación & 0 \\
\hline Teoría del Pensamiento Contable y las Organizaciones & 4 \\
\hline Entorno Económico y Geopolítico de los Negocios Internacionales & 4 \\
\hline Epistemología Contable & 4 \\
\hline Investigación I & 2 \\
\hline Total & 14 \\
\hline \multicolumn{2}{|l|}{ SEGUNDO SEMESTRE } \\
\hline Asignatura & Créd. \\
\hline Análisis y Gestión de Costos & 3 \\
\hline Auditoría & 3 \\
\hline Seminario de Tributación & 3 \\
\hline Seminario de Normas Internacionales y Aseguramiento & 3 \\
\hline Investigación II & 2 \\
\hline Total & 14 \\
\hline \multicolumn{2}{|l|}{ TERCER SEMESTRE } \\
\hline Asignatura & Créd. \\
\hline Contabilidad Financiera & 2 \\
\hline Sistemas de Información & 2 \\
\hline Énfasis I & 6 \\
\hline Electiva I & 2 \\
\hline
\end{tabular}




\begin{tabular}{l|l}
\hline Investigación III & 2 \\
\hline Total & $\mathbf{1 4}$ \\
\hline CUARTO SEMESTRE & Créd. \\
\hline Asignatura & 4 \\
\hline Humanismo, Sociedad y Ética & 6 \\
\hline Énfasis II & 2 \\
\hline Electiva II & 4 \\
\hline Investigación IV & $\mathbf{1 4}$ \\
\hline Total & $\mathbf{5 6}$ \\
\hline Total créditos &
\end{tabular}

\section{UNIVERSIDAD LA GRAN COLOMBIA ${ }^{12}$}

Programa: Maestría en Contabilidad

Título: Magíster en Contabilidad

\section{Perfil del egresado:}

El magíster egresado de la Universidad La Gran Colombia se caracterizará por sus competencias para entender, aplicar e investigar los aspectos relacionados con el campo epistemológico y ontológico de la contabilidad, el control y las finanzas y las relaciones entre teoría y práctica, en el marco de la crítica, la ética, la contribución al mejoramiento de las condiciones de vida, el desarrollo económico y social de nuestro país y al desarrollo de la disciplina contable.

\section{Plan de estudios:}

12 Información tomada de la página web de la Facultad de Posgrados y Formación Continuada de la Universidad La Gran Colombia. 


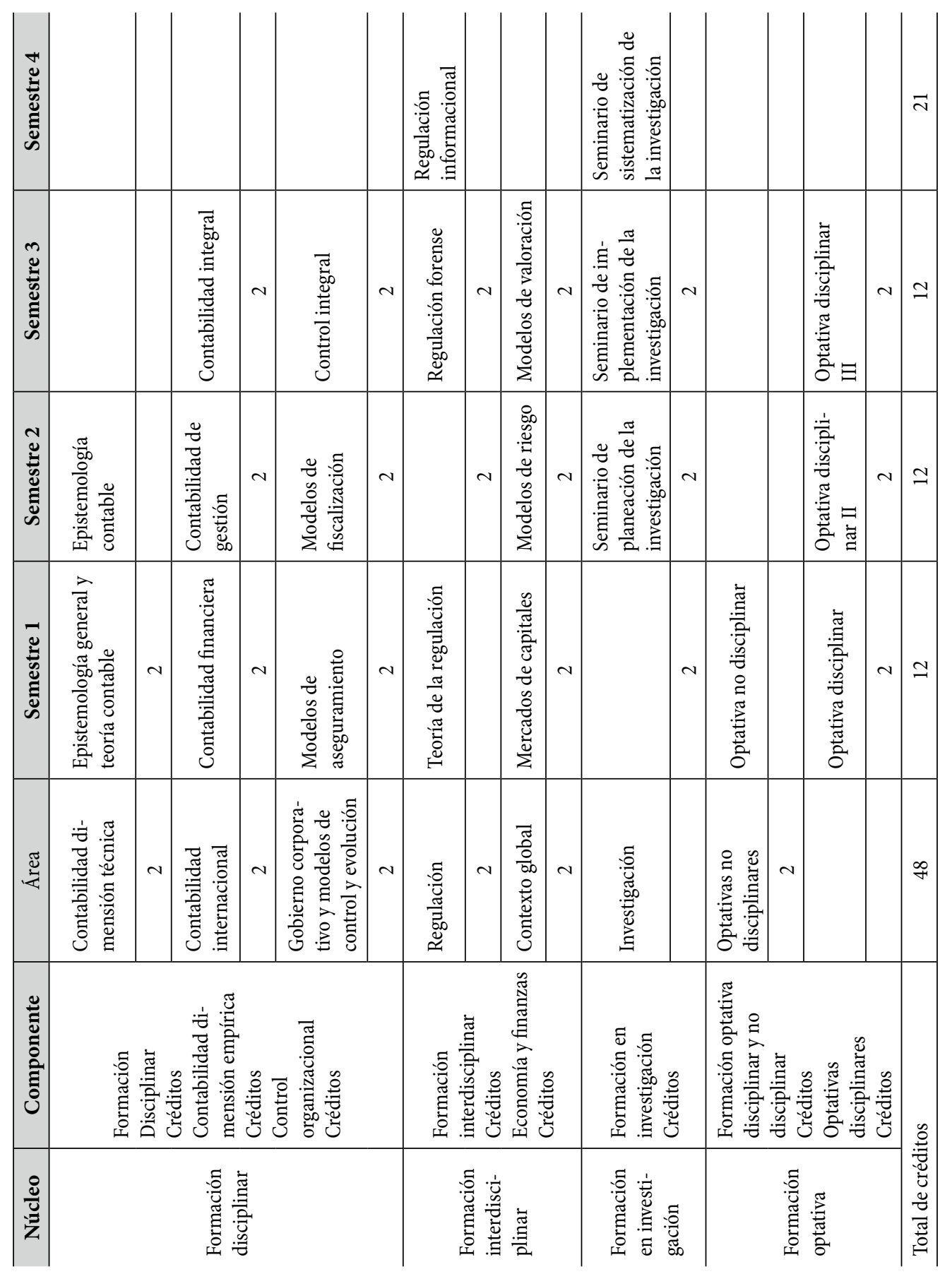

Revista Activos, ISSN: 01245805 e-ISSN: 2500-5278, Vol. 16 N. ${ }^{\circ} 31$, julio-diciembre de 2018, pp. 157-203 


\section{UNIVERSIDAD LIBRE ${ }^{13}$}

Programa: Maestría en Contabilidad

Título: Magíster en Contabilidad

\section{Perfil del egresado:}

Perfil disciplinar: preparado para asumir y buscar solución a problemáticas complejas de las organizaciones, propias de la medición, valoración, evaluación y control de la riqueza representada en el patrimonio, y de la información contable y financiera de los niveles micro y macro, en contextos globalizados, haciendo uso de los avances científicos y tecnológicos.

Perfil ocupacional: competente para liderar el diseño de procesos complejos de determinación e información contable y financiera de nivel micro y macro; para gerenciar y evaluar sistemas de información financiera y de control en escenarios internacionalizados; para influir en la construcción de metodologías que coadyuven el desarrollo científico y tecnológico del conocimiento contable; y para asumir los roles de gerencia institucional y sectorial, asesoría técnica y promocional para las organizaciones.

Perfil personal: persona íntegra, con claridad ética, valores ciudadanos, pensamiento abierto al cambio y a la innovación, crítico, persistente en la defensa de los mandatos de la ley y de la moral.

Perfil investigativo: formado para asumir con alta eficiencia sus responsabilidades en la docencia y la investigación; para desarrollar pensamiento crítico con enfoque holístico; para conocer, comprender y promover el estudio y desarrollo de las teorías, paradigmas y escuelas contables y financieras.

13 Información tomada de la página web de la Universidad Libre. 


\section{Plan de estudios:}

\begin{tabular}{|c|c|}
\hline PRIMER SEMESTRE & C.A \\
\hline Hermenéutica Contable * & 2 \\
\hline Teoría Contable & 2 \\
\hline Contametría Básica * & 2 \\
\hline Contexto Económico * & 2 \\
\hline Electiva I* & 2 \\
\hline Investigación * & 2 \\
\hline Total créditos & 12 \\
\hline SEGUNDO SEMESTRE & C.A \\
\hline Teoría de la Regulación * & 2 \\
\hline Pensamiento Contable * & 2 \\
\hline Regulación Comparada * & 2 \\
\hline Electiva II * & 2 \\
\hline Investigación II * & 2 \\
\hline Énfasis I (Contabilidad Forense) - Teoría de la Prueba & 2 \\
\hline Énfasis II (Contabilidad de Gestión) - Contabilidad Logística & 2 \\
\hline $\begin{array}{l}\text { Énfasis III (Contabilidad Financiera Internacional) - Contabilidad } \\
\text { Internacional }\end{array}$ & 2 \\
\hline Énfasis IV (Contabilidad Estatal) -Planeación y Presupuesto & 2 \\
\hline Total créditos & 12 \\
\hline TERCER SEMESTRE & C.A \\
\hline Tecnologías de la Información y la Comunicación * & 2 \\
\hline Contametría Dinámica * & 2 \\
\hline Electiva III* & 2 \\
\hline Investigación III * & 2 \\
\hline Énfasis I (Contabilidad Forense) - Responsabilidad Profesional & 2 \\
\hline Énfasis I (Contabilidad Forense) - Criminología & 2 \\
\hline Énfasis II (Contabilidad de Gestión) - Contabilidad de Gestión & 4 \\
\hline Énfasis III (Contabilidad Financiera Internacional) - Valor Razonable & 2 \\
\hline $\begin{array}{l}\text { Énfasis III (Contabilidad Financiera Internacional) - Estándares para } \\
\text { PyME }\end{array}$ & 2 \\
\hline
\end{tabular}




\begin{tabular}{l|c}
\hline Énfasis IV - Regulación Internacional & 2 \\
\hline Énfasis IV (Contabilidad Estatal) - Políticas Públicas & 2 \\
\hline Total créditos & $\mathbf{1 2}$ \\
\hline CUARTO SEMESTRE & C.A \\
\hline Responsabilidad Social ${ }^{\star}$ & 2 \\
\hline Electiva IV $^{*}$ & 2 \\
\hline Investigación IV* & 4 \\
\hline Énfasis I (Contabilidad Forense) - Contabilidad Forense & 4 \\
\hline Énfasis II (Contabilidad de Gestión) - Modelos de Decisión & 2 \\
\hline Énfasis II (Contabilidad de Gestión) - Contabilidad Regulatoria & 2 \\
\hline Énfasis III (Contabilidad Financiera Internacional) - Estándares & 4 \\
Internacionales & 4 \\
\hline Énfasis IV (Contabilidad Estatal) - Contabilidad Internacional & $\mathbf{1 2}$ \\
\hline Total créditos & $\mathbf{4 8}$ \\
\hline Total créditos maestría & 4 \\
\hline
\end{tabular}

\section{UNIVERSIDAD DE MEDELLÍN ${ }^{14}$}

Programa: Maestría en Contabilidad Internacional y de Gestión

Título: Magíster en Contabilidad Internacional y de Gestión

\section{Perfil del egresado:}

El magíster en Contabilidad Internacional y de Gestión egresado de la Universidad de Medellín será un experto en gestionar, transferir y comunicar información y conocimiento contable desde la interpretación de los modelos de contabilidad financiera bajo estándares internacionales y de la contabilidad de gestión.

14 Información tomada de la página web de la Universidad de Medellín. 
El magíster en Contabilidad Internacional y de Gestión estará formado en los modelos de regulación contable bajo estándares internacionales, en los modelos contables de medición y desempeño, en herramientas para la generación de información, en pensamiento sistémico, en estudio de teorías y paradigmas que permean la contabilidad, en la forma de gerenciar los sistemas de información y en otros conocimientos, que le permitirán comprender, interpretar y argumentar los modelos de regulación contable, para resolver las problemáticas de reconocimiento, medición, revelación y especialmente lo relacionado con la utilidad de la información financiera. Además, el magíster estará en capacidad de liderar el sistema de información contable para gestionar conocimiento útil que le permita apoyar y participar de forma efectiva en la toma de decisiones en las etapas de planeación, ejecución, dirección y control para identificar oportunidades de mejora y de forma consecuente para una mayor rentabilidad, sostenibilidad y competitividad de las organizaciones bien sean públicas o privadas.

\section{Plan de estudios:}

\begin{tabular}{l|c}
\hline PRIMER SEMESTRE & Créditos \\
\hline Seminarios & 2 \\
\hline Fundamentos teóricos de la regulación contable internacional & 3 \\
\hline Modelos de regulación contable internacional I & 2 \\
\hline Modelos de regulación contable internacional II & 2 \\
\hline Modelos de regulación contable internacional III & 2 \\
\hline Modelos de regulación contable internacional IV & $\mathbf{1 1}$ \\
\hline Subtotal & Créditos \\
\hline SEGUNDO SEMESTRE & 2 \\
\hline Seminarios & 3 \\
\hline Trabajo de Grado I & 2 \\
\hline Modelos de regulación contable internacional V & 2 \\
\hline Hermenéutica Contable & 2 \\
\hline Evaluación financiera en los modelos de regulación contable & $\mathbf{1 1}$ \\
\hline internacional & \\
\hline Serencia de Sistemas de Información Contable & \\
\hline
\end{tabular}




\begin{tabular}{l|c}
\hline \multicolumn{1}{l}{ TERCER SEMESTRE } & Créditos \\
\hline Seminarios & 2 \\
\hline Trabajo de Grado II & 2 \\
\hline Contabilidad de Gestión I & 2 \\
\hline Contabilidad de Gestión II & 2 \\
\hline Contabilidad de Gestión III & 2 \\
\hline Contabilidad de Gestión IV & $\mathbf{1 0}$ \\
\hline Subtotal & Créditos \\
\hline CUARTO SEMESTRE & 2 \\
\hline Seminarios & 2 \\
\hline Trabajo de Grado III & 2 \\
\hline Contabilidad de Gestión V & 2 \\
\hline Énfasis I (Electiva) & 2 \\
\hline Énfasis II (Electiva) & $\mathbf{1 0}$ \\
\hline Énfasis III (Electiva) & $\mathbf{4 2}$ \\
\hline Subtotal &
\end{tabular}

\section{UNIVERSIDAD ICESI ${ }^{15}$}

Programa: Maestría en Contabilidad y Tributación

Título: Magíster en Contabilidad y Tributación

\section{Perfil del egresado:}

Profesionales con avanzados conocimientos y capacidad para optimizar la toma de decisiones en las áreas contable, tributaria y financiera, en los contextos nacional e internacional, evaluando y gestionando el riesgo, dentro de un marco de actuación socialmente ético y responsable.

\footnotetext{
15 Información tomada de la página web de la Universidad ICESI.
} 


\section{Plan de estudios:}

\begin{tabular}{|c|c|c|c|}
\hline \multicolumn{2}{|c|}{ Año 1} & \multicolumn{2}{|c|}{ Año 2} \\
\hline Semestre 1 & Semestre 2 & Semestre 3 & Semestre 4 \\
\hline $\begin{array}{l}\text { Teoría de la regula- } \\
\text { ción contable }\end{array}$ & $\begin{array}{l}\text { Comunicaciones } \\
\text { gerenciales }\end{array}$ & $\begin{array}{l}\text { Estados e instru- } \\
\text { mentos financieros }\end{array}$ & $\begin{array}{l}\text { Regulación } \\
\text { comparada }\end{array}$ \\
\hline $\begin{array}{l}\text { Políticas contables } \\
\text { y activos }\end{array}$ & $\begin{array}{l}\text { Métodos de } \\
\text { medición de valor } \\
\text { y riesgo }\end{array}$ & $\begin{array}{l}\text { Estándares interna- } \\
\text { cionales de audito- } \\
\text { ría y aseguramiento }\end{array}$ & $\begin{array}{l}\text { Ética y responsabi- } \\
\text { lidad social }\end{array}$ \\
\hline $\begin{array}{l}\text { Estrategia } \\
\text { financiera }\end{array}$ & $\begin{array}{l}\text { Reconocimiento y } \\
\text { medición }\end{array}$ & $\begin{array}{l}\text { Procedimiento } \\
\text { y planeación } \\
\text { tributaria } \\
\text { Proyecto de grado I }\end{array}$ & Electivas I, II y III \\
\hline $\begin{array}{l}\text { Derecho contrac- } \\
\text { tual y societario }\end{array}$ & $\begin{array}{l}\text { Administración es- } \\
\text { tratégica de costos }\end{array}$ & & Proyecto de grado II \\
\hline \multirow[t]{2}{*}{$\begin{array}{l}\text { Fundamentos } \\
\text { de estadística y } \\
\text { econometría }\end{array}$} & $\begin{array}{l}\text { Gobierno corpora- } \\
\text { tivo y control }\end{array}$ & & \\
\hline & $\begin{array}{l}\text { Tributación } \\
\text { nacional }\end{array}$ & & \\
\hline
\end{tabular}

Total créditos: 50

\section{Anexo 3. Programas pregrado Contaduría Pública}

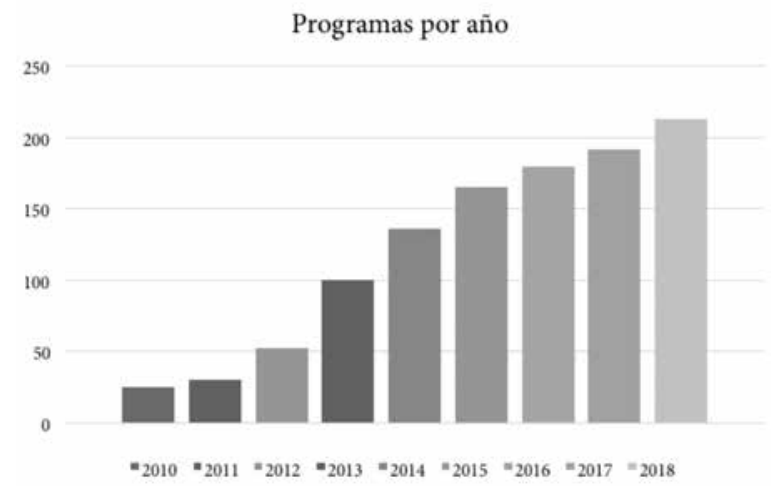

Fuente: elaboración propia con base en datos SNIES, MEN (2018). 


\section{Anexo 4. Estudiantes matriculados pregrado Contaduría}

Pública

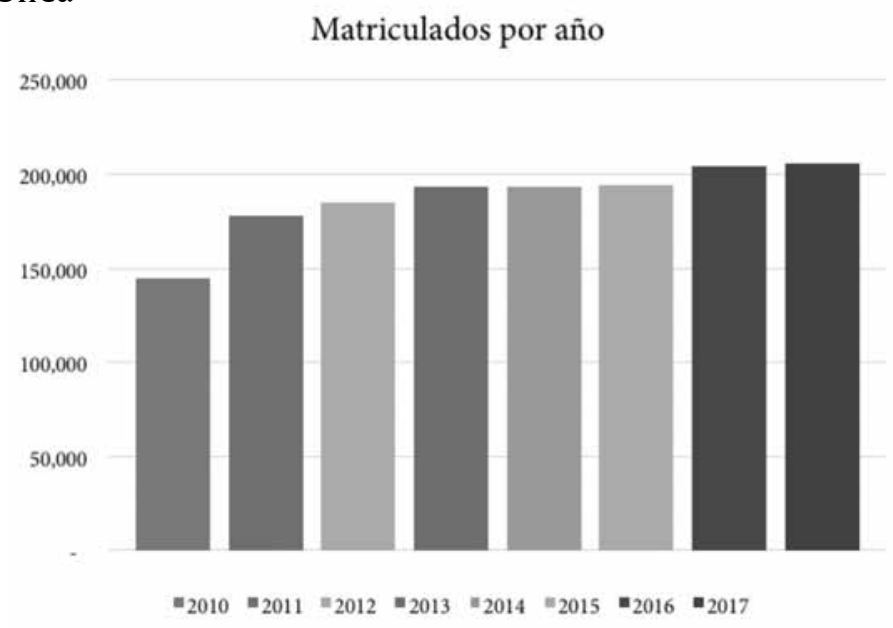

Fuente: elaboración propia con base en datos SNIES, MEN (2018).

\section{Anexo 5. Programas Maestría en Contabilidad}

\section{Programas por año}

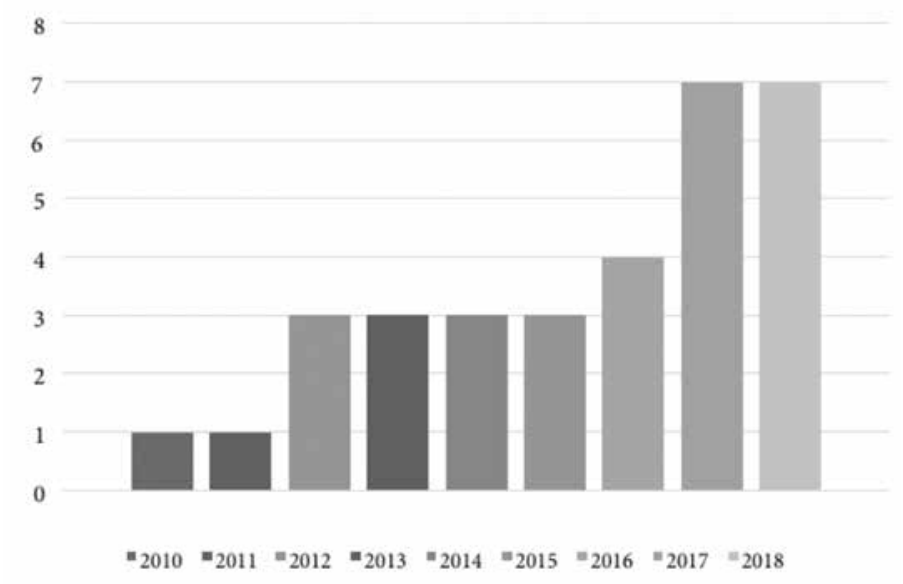

Fuente: elaboración propia con base en datos SNIES, MEN (2018). 


\section{Anexo 6. Estudiantes matriculados Maestría en Contabilidad}

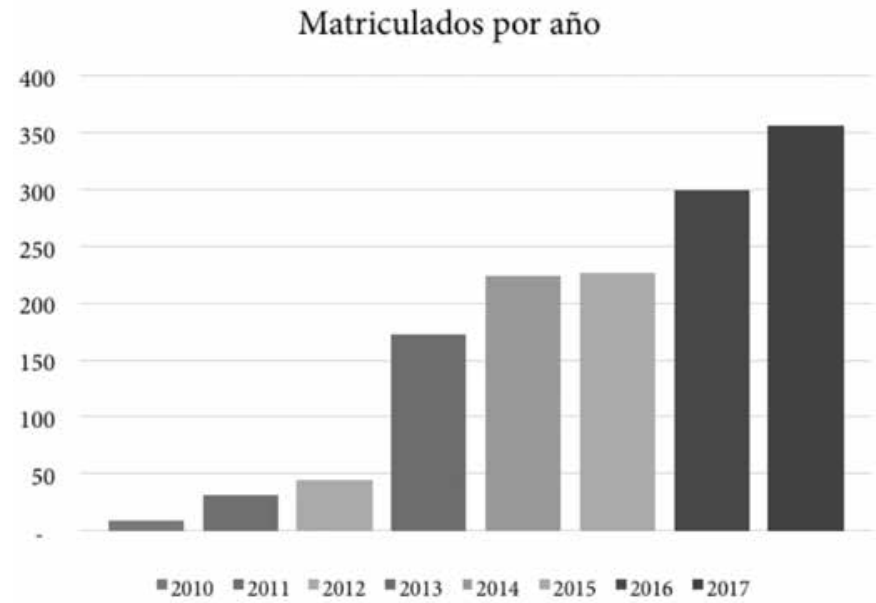

Fuente: elaboración propia con base en datos SNIES, MEN (2018). 